\title{
Sugarcane leaf photosynthetic light responses and their difference between varieties under high temperature stress
}

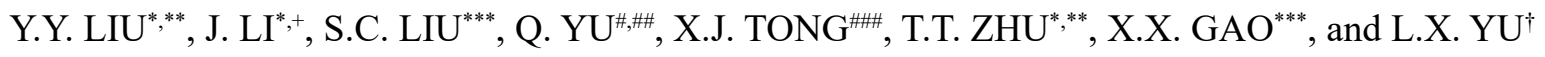 \\ Key Laboratory of Water Cycle and Related Land Surface Processes, Institute of Geographic Sciences and Natural \\ Resources Research, Chinese Academy of Sciences, 100101 Beijing, China* \\ College of Resources and Environment, University of Chinese Academy of Sciences, 100049 Beijing, China** \\ Sugarcane Research Institute, Yunnan Academy of Agricultural Sciences, 661600 Kaiyuan, Yunnan, China*** \\ State Key Laboratory of Soil Erosion and Dryland Farming on the Loess Plateau, Institute of Soil and Water \\ Conservation, Northwest Agriculture and Forestry University, 712100 Yangling, Shaanxi, China ${ }^{\#}$ \\ School of Life Sciences, University of Technology Sydney, 2007 NSW, Australia ${ }^{\# \#}$ \\ College of Forestry, Beijing Forestry University, 100083 Beijing, China ${ }^{\# \#}$ \\ Yunnan Climate Center, 650034 Kunming, Yunnan, China ${ }^{\dagger}$
}

\begin{abstract}
Leaf photosynthetic light response (PLR) of six sugarcane (Saccharum officinarum L.) varieties with a high sugar content was measured in the field. PLR curves were fitted by the rectangular hyperbola $(\mathrm{RH})$ model, the nonrectangular hyperbola (NRH) model, and the Ye model, respectively. Photoinhibition occurred under warm and humid environment for all tested sugarcane varieties except for GT02-467 with the photosynthetic rate reduced significantly. The Ye model was the best for PLR curve fitting, especially when photoinhibition occurred. Nearly all PLR parameters estimated by the Ye model were better than the other two models. Some PLR parameters correlated with each other. A significant negative correlation was found between the photoinhibition coefficient and the photosaturation coefficient. The varieties with high light-use efficiency (e.g., YZ99-91 and YZ01-1413) are suitable for dense planting under warming climate, while the varieties with strong ability for dim light use (e.g., GT02-467 and MT69-421) would be appropriate for planting at a high density under warming and dimming climate in the future.
\end{abstract}

Additional key words: dark respiration rate; light-compensation point; light-saturation point; maximum gross photosynthetic rate.

\section{Introduction}

Photosynthetic rate is dependent on the available PPFD and can be described by a photosynthetic light-response (PLR) curve. Several equation forms were used to describe the PLR curve, including the rectangular hyperbola (RH) model (Baly 1935, Thornley 1998), the nonrectangular hyperbola (NRH) model (Thornley 1976, Leverenz and Jarvis 1979), the exponential model (Prado et al. 1997, Rascher et al. 2000), and the modified rectangular hyperbola model (Ye model) (Ye 2007, Lobo et al. 2013). Among these forms, the NRH model was the most popular (Hirose and Werger 1987, Nepstad et al. 2002). The photosynthetic rate responds to increasing PPFD following an asymptotic curve when the PLR curve is simulated by the RH model, the NRH model, and the exponential model. These three PLR curves could not lead to the determination of a light-saturation point $\left(\mathrm{I}_{\mathrm{S}}\right)$, resulting in the overestimation of maximum photosynthetic capacity (Kyei-Boahen et al. 2003, Leakey et al. 2006, Koyama and Kikuzawa 2010). These three models could not also predict the photoinhibition of photosynthesis (Bassman and Zwier 1991, Bruzzese et al. 2010, Lang et al. 2013), the kinetic downregulation of PSII, and light adaptation (Ye et al. 2014). The Ye model (Ye 2007) solved these problems well and was widely used in studies of photosynthesis in crops and trees (e.g., Lang et al. 2013), and generally performed better than other models. However, the ability of this equation form to correctly describe sugarcane (Saccharum officinarum L.) PLR has not yet been reported.

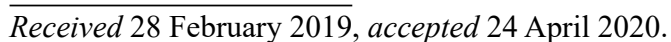

${ }^{+}$Corresponding author; phone: +86 10 64888951, fax: +86 10 64881844, e-mail: lijun@igsnrr.ac.cn

Abbreviations: $\mathrm{I}_{\mathrm{C}}-$ light-compensation point; $\mathrm{I}_{\mathrm{S}}$ - light-saturation point; $P_{\mathrm{N}}-$ net photosynthetic rate; $P_{\mathrm{gmax}}-$ maximum gross photosynthetic rate at light-saturation point; $R_{\mathrm{D}}$ - dark respiration rate; rh - relative humidity in the leaf chamber; SWC - relative soil water content; $T_{\mathrm{a}}$ - air temperature in the leaf chamber; $\alpha$-initial light-use efficiency; $\beta$ - photoinhibition coefficient; $\gamma$ - photosaturation coefficient.

Acknowledgements: This study was sponsored by the Strategic Priority Research Program of Chinese Academy of Sciences, Pan-Third Pole Environment Study for a Green Silk Road (XDA20040301), and Special Scientific Research Fund of Meteorological Public Welfare Profession of China (GYHY201406030). We also acknowledge the editor and two anonymous reviewers for their constructive comments on the manuscript. 
Gunasekera et al. (2013) studied rubber photosynthesis and found that some of the parameters in the exponential model were closely related to each other. For instance, maximum gross photosynthetic rate $\left(P_{\text {gmax }}\right)$ correlated with $\mathrm{I}_{\mathrm{S}}$ and light-compensation point $\left(\mathrm{I}_{\mathrm{C}}\right)$, initial light-use efficiency $(\alpha)$ correlated with dark respiration $\left(R_{\mathrm{D}}\right)$ and $\mathrm{I}_{\mathrm{S}}$, and $R_{\mathrm{D}}$ correlated with $\mathrm{I}_{\mathrm{C}}$ and $\mathrm{I}_{\mathrm{S}}$. Similar results were found in the Ye model. Theoretical analysis showed that the photoinhibition coefficient $(\beta)$ was inversely proportional to $I_{S}$ while the photosaturation coefficient $(\gamma)$ was constant (Ye and Kang 2012). The relationships between PLR parameters were rarely studied.

Plant photosynthesis is sensitive to temperature changes. There is an optimum crop-specific temperature range for photosynthesis. For sugarcane growing in tropical and subtropical regions, the optimum temperature for photosynthesis is $27-35^{\circ} \mathrm{C}$ (Moore and Botha 2014). In the context of global climate change, China is expected to experience a warming trend, which in the future could produce maximum air temperatures that would be frequently higher than that optimal for sugarcane photosynthesis. Under higher temperature stress, photosynthetic photoinhibition occurred (Salvucci and Crafts-Brandner 2004, Greer and Weedon 2012), leading to the decline in $P_{\text {gmax }}$ and $\alpha$ (Berry and Björkman 1980, Greer and Weedon 2012). $\mathrm{I}_{\mathrm{S}}$ and $\mathrm{I}_{\mathrm{C}}$ increased for some plants such as Picea glauca (Man and Lieffers 1997) but decreased for other plants such as Castanopsis tibetana that can adapt to high temperature stress because small $\mathrm{I}_{\mathrm{S}}$ and $\mathrm{I}_{\mathrm{C}}$ may allow these plants to achieve higher photosynthetic rates at low PPFD levels (Zhang and Luo 2016).

Different species of plants show different photosynthetic characteristics. The $P_{\text {gmax }}$ of $\mathrm{C}_{4}$ plants is significantly higher than that of $\mathrm{C}_{3}$ plants. Maize and sugarcane are both $\mathrm{C}_{4}$ crops, but $P_{\text {gmax }}$ of maize is higher than that of sugarcane (Sun and Sweet 1996, Crafts-Brandner and Salvucci 2002). Leaves of different varieties of the same species can also have different PLR parameters (Read and Hill 1985, Dwyer et al. 1995, Sun and Sweet 1996). Published results showed that the $P_{\text {gmax }}$ of sugarcane varieties varied from 19 to $39 \mu \mathrm{mol}\left(\mathrm{CO}_{2}\right) \mathrm{m}^{-2} \mathrm{~s}^{-1}$ (Moore and Botha 2014). Since the photosynthetic characteristics of crops affect yield and quality, photosynthetic characteristics of different varieties must be fully considered in crop growth simulations, crop breeding, and cultivation management.

As a $\mathrm{C}_{4}$ plant growing in tropical and subtropical regions and manifesting high photosynthetic capacity, sugarcane exhibits the characteristics of high $\mathrm{I}_{\mathrm{s}}$, low $R_{\mathrm{D}}$, high light-use efficiency, and high yield (Inman-Bamber and Thompson 1989). Sugarcane is not only the most important sugar crop, but also produces an important raw material for the energy, chemical, and light industries. The objectives of this study were to compare different models of PLR for different sugarcane varieties, to investigate the relationship among PLR parameters, to determine how PLR change with high temperature stress, to study the PLR characteristics of different sugarcane varieties under high temperature. This study provides a method to study photosynthesis parameter values and their correlations using the Ye model. The results will provide a theoretical basis and data support for sugarcane growth simulation, cultivation management, and predicting sugarcane production. The results will also be of great significance for breeding high temperature resistant sugarcane varieties, coping with future climate change, and ensuring the safety of sugarcane production.

\section{Materials and methods}

Experiment site: The experiment was carried out in the sugarcane experimental field of the Sugarcane Research Institute, Yunnan Academy of Agricultural Sciences $\left(103^{\circ} 15^{\prime} \mathrm{N}, 23^{\circ} 42^{\prime} \mathrm{E}, 1055 \mathrm{~m}\right.$ a.s.l.). Located in Kaiyuan city, Yunnan province, the experimental site was on the south of the Yunnan Plateau and the central section of Honghe Prefecture. It experiences a subtropical monsoon climate, possessing the following climate characteristics: spring directly follows autumn, wide diurnal temperature range, obvious dry and wet seasons, frequent droughts. The experimental site has a mean annual air temperature of $19.8^{\circ} \mathrm{C}$, a mean annual precipitation of $740 \mathrm{~mm}$, an annual sunshine of $2,200 \mathrm{~h}$, and an annual frost-free period of $340 \mathrm{~d}$. The rainy season occurs from May to October, coinciding with the hot season. The mean annual temperature is relatively stable, with little interannual variation. Soil organic matter content is $20.5 \mathrm{~g} \mathrm{~kg}^{-1}$, total nitrogen content is $1.64 \mathrm{~g} \mathrm{~kg}^{-1}$, total phosphorus content is $0.67 \mathrm{~g} \mathrm{~kg}^{-1}$, total potassium content is $13.7 \mathrm{~g} \mathrm{~kg}^{-1}$, alkalihydrolyzed nitrogen content is $80.79 \mathrm{mg} \mathrm{kg}^{-1}$, available phosphorus content is $9.81 \mathrm{mg} \mathrm{kg}^{-1}$, available potassium content is $112.78 \mathrm{mg} \mathrm{kg}^{-1}$, and $\mathrm{pH}$ is 6.0 .

The sugarcane varieties used in this study were provided by Sugarcane Research Institute, Yunnan Academy of Agricultural Sciences. Some of their characteristics were listed in the text table below. Among these varieties, three (YZ series) were from Yunnan and others, GT02-467 and MT69-421, from Guangxi and Fujian, respectively. ROC22, comes from Taiwan, has good comprehensive characteristics, accounting for more than half of current sugarcane planting area in China. All varieties had a high

\begin{tabular}{lll}
\hline Variety & Origin & Characteristics \\
\hline ROC22 & Taiwan, dominant in China & mid-maturation, high cane yield \\
GT02-467 & Guangxi & wide leaf, early maturity, high cane yield \\
MT69-421 & Fujian & narrow leaf, mid-maturation, stable cane yield \\
YZ03-194 & Yunnan & slightly long leaf, mid-early maturity, high cane yield \\
YZ01-1413 & Yunnan & slightly wide leaf, mid-maturation, high cane yield \\
YZ99-91 & Yunnan & wide leaf, early maturity, medium-stable cane yield \\
\hline
\end{tabular}


sugar content in the cane. Most of them had a high cane yield except for MT69-421 and YZ99-91. The yields of these two varieties were not very high, but relatively stable. There were 18 plots ( 6 varieties $\times 3$ replicates $)$ at the experimental site. Each plot covered an area of $6 \times 8 \mathrm{~m}^{2}$. Row spacing was $1 \mathrm{~m}$ and planting density was 12,000 buds $\mathrm{ha}^{-1}$. A border of 1-2 rows of sugarcane was planted around the experimental area.

Photosynthesis measurements: Measurements of photosynthetic rate were made in the experimental plots over a 8-d period in July 2016 using an LI-6400XT portable photosynthesis measurement system (Li-Cor Inc., Nebraska, USA). The PLR for one variety was measured during one day. The second or third youngest, fully expanded, healthy leaves of representative plants were selected in each plot. One leaf was measured from each of the three replicate plots. All sugarcane varieties were in the same growth stage. During the measurement period, there was rainfall at night and sunshine in the daytime in most of days. Measurements were made between 9:00 to 12:00 h on sunny days.

The PPFD of the chamber light source of $L I-6400 X T$ was set to 2,$000 ; 1,800 ; 1,600 ; 1,400 ; 1,200 ; 900,600$, $400,200,150,100,50$, and $0 \mu \mathrm{mol} \mathrm{m} \mathrm{m}^{-2} \mathrm{~s}^{-1}$. The $\mathrm{CO}_{2}$ concentration in the chamber was maintained at $400 \mu \mathrm{mol}$ $\mathrm{mol}^{-1}$. Before the photosynthesis measurements began, the leaves were illuminated by PPFD of $2,000 \mu \mathrm{mol} \mathrm{m} \mathrm{m}^{-2} \mathrm{~s}^{-1}$ for about 15 min until a steady-state photosynthetic rate was reached. Leaves were maintained in their original positions during photosynthesis measurements. The measurement time at each PPFD value was set to $120-180 \mathrm{~s}$. In addition to photosynthetic rate, other data such as leaf temperature, chamber air temperature, chamber relative humidity, intercellular $\mathrm{CO}_{2}$ concentration, stomatal conductance, and soil water content in the $0-20-\mathrm{cm}$ depth were measured. PLR of two sugarcane varieties ROC22 and GT02-467 were also measured under different temperatures.

Analysis of leaf photosynthetic light-response curves: The PLR curves of sugarcane leaves were determined by the RH model, the NRH model, and the Ye model. Details of each model were given below.

The RH model is defined as:

$$
P_{\mathrm{N}}=\frac{\alpha \times P_{\text {gmax }} \times I}{P_{\text {gmax }}+\alpha \times I}-R_{\mathrm{D}}
$$

where $P_{\mathrm{N}}$ is the net photosynthetic rate $\left[\mu \mathrm{mol}\left(\mathrm{CO}_{2}\right) \mathrm{m}^{-2} \mathrm{~s}^{-1}\right]$, $P_{\text {gmax }}$ the maximum net photosynthetic capacity at light saturation $\left[\mu \mathrm{mol}\left(\mathrm{CO}_{2}\right) \mathrm{m}^{-2} \mathrm{~s}^{-1}\right], \alpha$ is the initial slope of the PLR curve, named the initial light-use efficiency $\left[\mu \mathrm{mol}\left(\mathrm{CO}_{2}\right) \mu \mathrm{mol}^{-1}\right], I$ the available photosynthetic photon flux density (PPFD) $\left[\mu \mathrm{mol} \mathrm{m} \mathrm{m}^{-2} \mathrm{~s}^{-1}\right.$, and $R_{\mathrm{D}}$ the dark respiration rate $\left[\mu \mathrm{mol}\left(\mathrm{CO}_{2}\right) \mathrm{m}^{-2} \mathrm{~s}^{-1}\right]$.

For $P_{\mathrm{N}}=0$, then:

$$
\text { IC }=\frac{R_{\mathrm{D}} \times P_{\text {gmax }}}{\alpha \times\left(P_{\text {gmax }}-R_{\mathrm{D}}\right)}
$$

For $P_{\mathrm{N}}=P_{\text {gmax }} / 2$, the half photosaturation point $(K)$ is:

$K=P_{\text {gmax }} / \alpha$

The NRH model is defined as:

$$
P_{\mathrm{N}}=\frac{\alpha \times I+P_{\text {gmax }}-\sqrt{\left(\alpha \times I+P_{\text {gmax }}\right)^{2}-4 \theta \times \alpha \times I \times P_{\text {gmax }}}}{2 \theta}-R_{\mathrm{D}}
$$

where $\theta$ is the convexity of the nonrectangular hyperbolic curve (between 0 and 1 ). When $\theta=0$, the PLR has the form of a rectangular hyperbola; when $\theta=1$, the relationship is transformed into a Blackman curve (Ogren 1993).

For $P_{\mathrm{N}}=0$, then:

IC $=\frac{P_{\text {gmax }} \times R_{\mathrm{D}}-\theta \times R_{\mathrm{D}}{ }^{2}}{\alpha \times\left(P_{\text {gmax }}-R_{\mathrm{D}}\right)}$

For $P_{\mathrm{N}}=P_{\text {gmax }} / 2$, then:

$K=\frac{2-\theta}{2 \times \alpha} \times P_{\text {gmax }}$

The Ye model is defined as:

$P_{\mathrm{N}}=\alpha \times \frac{1-\beta \times I}{1+\gamma \times I} \times I-R_{\mathrm{D}}$

where $\beta$ is the photoinhibition coefficient and $\gamma$ is the photosaturation coefficient. When $\beta=0$, there is no pole and photoinhibition in the PLR curve. When $\gamma=\alpha / P_{\text {gmax }}$, the Ye model degenerates into the RH model (Ye and Kang 2012).

For $P_{\mathrm{N}}=0$, then:

$\mathrm{IC}_{\mathrm{C}}=\frac{\alpha-R_{\mathrm{D}} \times \gamma-\sqrt{\left(\alpha-R_{\mathrm{D}} \times \gamma\right)^{2}-4 \alpha \times \beta \times R_{\mathrm{D}}}}{2 \alpha \times \beta}$

For $\mathrm{d}\left(P_{\mathrm{N}}\right) / \mathrm{d}(I)=0$, then:

Is $=\frac{\sqrt{(\beta+\gamma) / \beta}-1}{\gamma}$

For $I=\mathrm{I}_{\mathrm{S}}$, then:

$P_{\operatorname{gmax}}=\alpha \times\left(\frac{\sqrt{\beta+\gamma}-\sqrt{\beta}}{\gamma}\right)^{2}-R_{\mathrm{D}}$

The three leaf photosynthesis measurements for each variety at each light level were averaged to provide the data for PLR curve fitting to compare PLR models, determine correlations between PLR parameters, and determine effects of high temperature stress on PLR. PLR curves were fitted for each repeated observation to test the significance of their difference among six sugarcane varieties and between two temperature levels.

After fitting the three PLR models to the measured data, we chose the model, which fit best the measured data to conduct further investigations regarding temperature effects on photosynthetic parameters. The correlation and significant relationships between photosynthetic para- 
meters were analyzed by one-dimensional linear regression, and analysis of variance $(A N O V A)$ of the parameters was performed followed by mean separation analysis with Duncan's Multiple Range Test (DMRT) using the SPSS 13.0 statistical software (IBM Inc., USA).

\section{Results}

Comparison of PLR curves simulated by different models: Leaf temperatures of six sugarcane varieties during the measurement periods ranged from 34 to $39^{\circ} \mathrm{C}$. The results showed that five of the sugarcane varieties (all except GT02-467) exhibited declining leaf photosynthetic rate with increasing PPFD after PPFD reached the $\mathrm{I}_{S}$ and photoinhibition occurred (Fig. 1). Both the RH and NRH models did not account for photoinhibition, and therefore overestimated $P_{\mathrm{N}}$ at high PPFD values $(>1,600 \mu \mathrm{mol}$ $\left.\mathrm{m}^{-2} \mathrm{~s}^{-1}\right)$. However, the Ye model fitted the measured $P_{\mathrm{N}}$ well at all PPFD levels (Fig. 1). The determination coefficient $\left(r^{2}\right)$ for the PLR curves fitted by the Ye model was greater than those for the RH and NRH models (average values of $1.000,0.983$, and 0.995, respectively) (Table 1). Because
GT02-467 showed no signs of photoinhibition, the curve fitting results were close to the measured values and the $r^{2}$ of the curve fitted by NRH model was essentially the same as for the curve fitted by the Ye model (0.999 and 1.000, respectively).

For all sugarcane varieties, the $P_{\text {gmax }}$ simulated by the RH model and the NRH model were greater than the measured values by $33.8-57.3 \%$ and $2.7-17.7 \%$, respectively. The $P_{\text {gmax }}$ fitted by the Ye model was almost the same as the measured value (less than $2 \%$ difference), identifying this model as the best of the three models as far as estimating this parameter. The $\alpha$ fitted by the RH and Ye models were respectively about 82 and $19 \%$ higher than the measured values, while $\alpha$ fitted by the NRH model was $8 \%$ lower than the measured values, identifying the $\mathrm{NRH}$ model as the best model for estimating $\alpha$. The best model for determining $\mathrm{I}_{\mathrm{C}}$ was the Ye model, with $\mathrm{I}_{\mathrm{C}}$ underestimated by $3.4 \%$, and the $\mathrm{RH}$ and NRH models underestimating $\mathrm{I}_{\mathrm{C}}$ by 6.2 and $6.3 \%$, respectively. The $\mathrm{RH}$ and NRH models were not able to estimate $\mathrm{I}_{\mathrm{S}}$, and only $K$ can be calculated. In contrast, the Ye model determines $I_{S}$ directly, and provided values very close to the measured

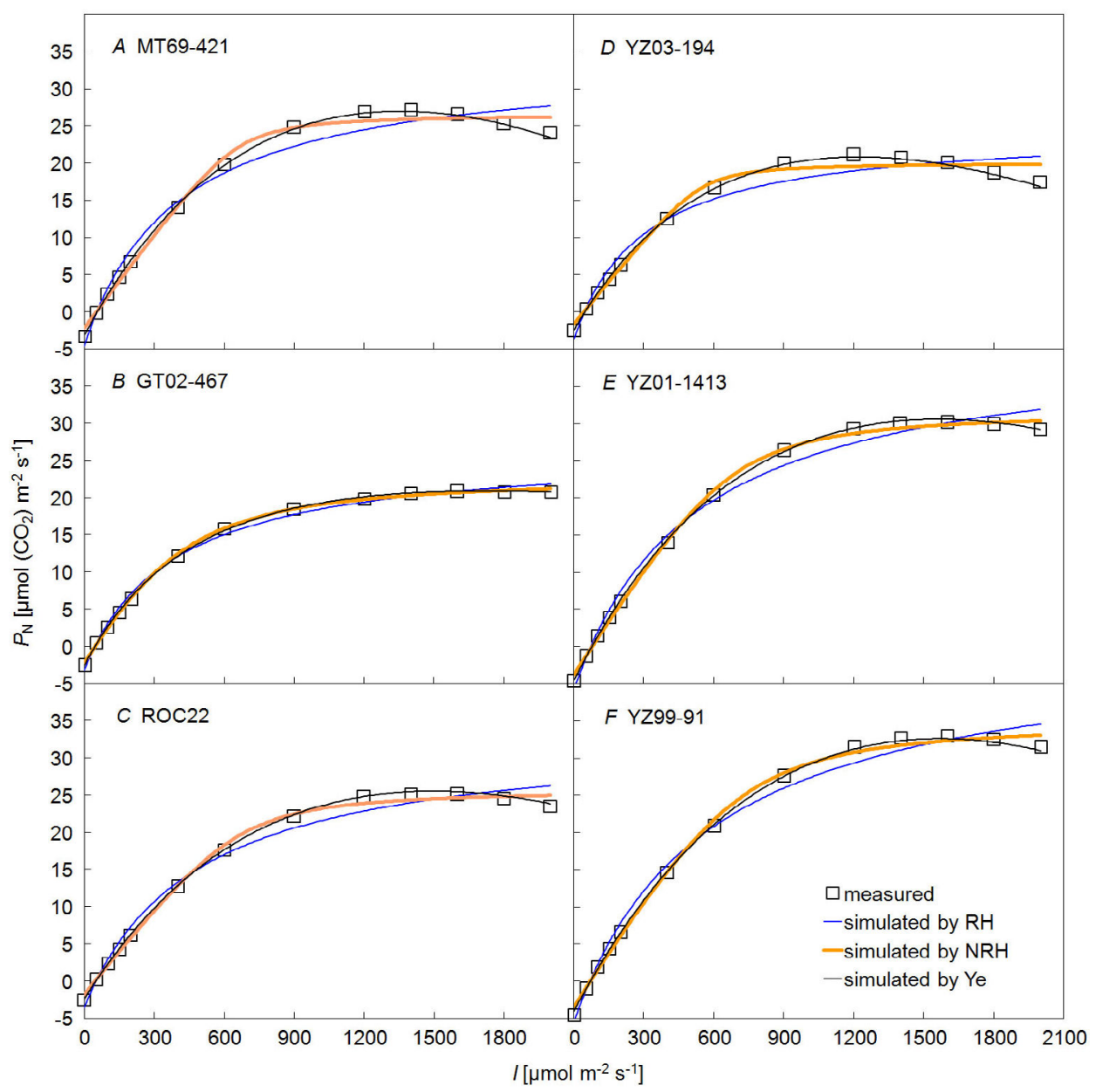

Fig. 1. Photosynthetic light-response curves of six sugarcane varieties fitted by different models. Data points were the average of three replications of measurement. $P_{\mathrm{N}}$ - net photosynthetic rate, $I$ - available photosynthetic photon flux density (PPFD), RH - rectangular hyperbola model, NRH - nonrectangular hyperbola model, Ye - Ye model. 
Table 1. Parameters for three photosynthetic light-response models fitted to leaf photosynthetic rate data measured on six sugarcane varieties. Measurements were taken at temperatures ranging from $34-39^{\circ} \mathrm{C}$. The values in the table were fitted from mean net photosynthetic rate of three repeated measurements. $P_{\text {gmax }}$ - maximum gross photosynthetic capacity $\left[\mu \operatorname{mol}\left(\mathrm{CO}_{2}\right) \mathrm{m}^{-2} \mathrm{~s}^{-1}\right] ; \alpha-$ initial light-use efficiency $\left[\mu \mathrm{mol}\left(\mathrm{CO}_{2}\right) \mu \mathrm{mol}^{-1}\right] ; \theta$ - convexity of nonrectangular hyperbolic curve, between $0-1 ; \beta$ - photoinhibition coefficient; $\gamma$ - photosaturation coefficient; $R_{\mathrm{D}}$ - dark respiration rate $\left[\mu \mathrm{mol}\left(\mathrm{CO}_{2}\right) \mathrm{m}^{-2} \mathrm{~s}^{-1}\right] ; \mathrm{I}_{\mathrm{S}}-$ light-saturation point $\left[\mu \mathrm{mol} \mathrm{m}^{-2} \mathrm{~s}^{-1}\right] ; \mathrm{I}_{\mathrm{C}}-$ lightcompensation point $\left[\mu \mathrm{mol} \mathrm{m}^{-2} \mathrm{~s}^{-1}\right] ; K$ - light half-saturation point $\left[\mu \mathrm{mol} \mathrm{m}^{-2} \mathrm{~s}^{-1}\right] ; r^{2}$ - determination coefficient; ND - no data.

\begin{tabular}{|c|c|c|c|c|c|c|c|c|c|c|c|}
\hline \multirow[t]{2}{*}{ Variety } & \multirow[t]{2}{*}{ Method } & \multicolumn{9}{|c|}{ Light-response parameter } & \multirow[t]{2}{*}{$r^{2}$} \\
\hline & & $P_{\operatorname{gmax}}$ & $\alpha$ & $\theta$ & $\beta\left(\times 10^{-4}\right)$ & $\gamma\left(\times 10^{-4}\right)$ & $R_{\mathrm{D}}$ & $K$ & $\mathrm{I}_{\mathrm{S}}$ & $\mathrm{I}_{\mathrm{C}}$ & \\
\hline \multirow[t]{4}{*}{ YZ99-91 } & RH model & 51.66 & 0.089 & ND & ND & ND & 5.51 & 578 & ND & 69 & 0.990 \\
\hline & NRH model & 38.45 & 0.049 & 0.911 & ND & ND & 3.46 & 428 & ND & 71 & 0.997 \\
\hline & Ye model & 32.60 & 0.060 & ND & 2.5 & 3.5 & 4.07 & ND & 1,569 & 71 & 1.000 \\
\hline & Measurement & 33.04 & 0.055 & ND & ND & ND & 4.10 & ND & 1,575 & 74 & ND \\
\hline \multirow[t]{4}{*}{ YZ03-194 } & RH model & 28.28 & 0.094 & ND & ND & ND & 3.70 & 300 & ND & 45 & 0.961 \\
\hline & NRH model & 21.69 & 0.038 & 0.972 & ND & ND & 1.67 & 291 & ND & 44 & 0.985 \\
\hline & Ye model & 20.80 & 0.054 & ND & 2.9 & 6.7 & 2.43 & ND & 1,223 & 47 & 1.000 \\
\hline & Measurement & 21.13 & 0.043 & ND & ND & ND & 2.11 & ND & 1,200 & 49 & ND \\
\hline \multirow[t]{4}{*}{ YZ01-1413 } & RH model & 47.41 & 0.092 & ND & ND & ND & 5.83 & 515 & ND & 72 & 0.989 \\
\hline & NRH model & 35.46 & 0.048 & 0.926 & ND & ND & 3.76 & 394 & ND & 79 & 0.998 \\
\hline & Ye model & 30.54 & 0.062 & ND & 2.3 & 5.0 & 4.54 & ND & 1,563 & 77 & 1.000 \\
\hline & Measurement & 30.13 & 0.054 & ND & ND & ND & 4.29 & ND & 1,520 & 80 & ND \\
\hline \multirow[t]{4}{*}{ MT69-421 } & RH model & 38.81 & 0.097 & ND & ND & ND & 4.66 & 399 & ND & 54 & 0.976 \\
\hline & NRH model & 28.81 & 0.042 & 0.972 & ND & ND & 2.23 & 349 & ND & 53 & 0.993 \\
\hline & Ye model & 26.96 & 0.059 & ND & 2.8 & 4.7 & 3.19 & ND & 1,355 & 57 & 1.000 \\
\hline & Measurement & 27.10 & 0.050 & ND & ND & ND & 2.94 & ND & 1,320 & 59 & ND \\
\hline \multirow[t]{4}{*}{ GT02-467 } & RH model & 29.74 & 0.078 & ND & ND & ND & 3.17 & 381 & ND & 45 & 0.995 \\
\hline & NRH model & 25.26 & 0.049 & 0.750 & ND & ND & 2.26 & 319 & ND & 47 & 0.999 \\
\hline & Ye model & 20.90 & 0.061 & ND & 1.3 & 14.3 & 2.61 & ND & 1,723 & 46 & 1.000 \\
\hline & Measurement & ND & 0.044 & ND & ND & ND & 2.12 & ND & ND & 48 & ND \\
\hline \multirow[t]{4}{*}{ ROC22 } & RH model & 36.92 & 0.077 & ND & ND & ND & 3.56 & 478 & ND & 51 & 0.985 \\
\hline & NRH model & 27.63 & 0.039 & 0.938 & ND & ND & 1.80 & 377 & ND & 47 & 0.996 \\
\hline & Ye model & 25.52 & 0.050 & ND & 2.4 & 5.2 & 2.41 & ND & 1,496 & 50 & 1.000 \\
\hline & Measurement & 25.17 & 0.043 & ND & ND & ND & 2.22 & ND & 1,450 & 51 & ND \\
\hline
\end{tabular}

values. The $R_{\mathrm{D}}$ fitted by the $\mathrm{RH}$ and Ye models were, respectively, about 49 and $8 \%$ higher than the measured values, while the NRH model estimates of this parameter were $15 \%$ lower than the measured values. The Ye model provided the best simulation of $R_{\mathrm{D}}$ (Table 1). In general, the Ye model provided the best estimates of the PLR curvefitting parameters, followed by the NRH model, with the RH model being the worst.

Correlation analysis of photosynthetic light-response parameters: We determined correlations between PLR parameters by using the parameters generated when the Ye model form was fit to the measured photosynthesis rate data. The results (Table 2) show that $P_{\text {gmax }}$ was positively correlated with $R_{\mathrm{D}}(P<0.05), \mathrm{I}_{\mathrm{C}}$ had a significant positive correlation with $R_{\mathrm{D}}(P<0.001)$, and $\beta$ was significantly negatively correlated with $\gamma$ and $\mathrm{I}_{\mathrm{S}}(P<0.01)$. The correlations between other parameters were not significant. In addition, there was a significant positive correlation between $R_{\mathrm{D}} / \mathrm{I}_{\mathrm{C}}$ and $\alpha(P<0.001)$ (Fig. 2$)$.
Effects of high temperature stress on photosynthetic light response: The responses of sugarcane leaf PLR to temperature increase differed between varieties. The observations revealed that the PLR of GT02-467 was greatly affected by high temperatures (Fig. 3 ). The $P_{\text {gmax }}$ at about $35^{\circ} \mathrm{C}$ was about $20 \%$ lower than that about $30^{\circ} \mathrm{C}$, but there was no significant photoinhibition at either temperature. High temperature had little effect on the PLR of ROC22. At low PPFD $\left(<1,000 \mu \mathrm{mol} \mathrm{m}^{-2} \mathrm{~s}^{-1}\right)$, the net photosynthetic rate of ROC22 was slightly lower at $34.5^{\circ} \mathrm{C}$ than that at $29.3^{\circ} \mathrm{C}$, while under higher PPFD, the net photosynthetic rates of ROC22 were not different due to temperature. The photoinhibition, although slight, was more obvious under the higher temperature.

The $P_{\operatorname{gmax}}$ of GT02-467 decreased by $23 \%$ when the temperature increased from about $30^{\circ} \mathrm{C}$ to about $35^{\circ} \mathrm{C}$ (Table 3), while $P_{\operatorname{gmax}}$ for ROC22 remained unchanged. Under high temperatures, GT02-467 was less able to use strong light for photosynthesis, but there was little effect on ROC22 photosynthesis at high PPFD levels. When high 
Table 2. Correlation coefficients of photosynthetic light-response parameters obtained by the Ye model. The parameter abbreviations and symbols were defined in Table $1 .{ }^{*},{ }^{* *}$, and ${ }^{* * *}$ mean the significant correlations at $0.05,0.01$, and 0.001 levels, respectively.

\begin{tabular}{lcrrrrr}
\hline Parameter & \multicolumn{1}{c}{$P_{\text {gmax }}$} & \multicolumn{1}{c}{$\alpha$} & $\beta$ & $\gamma$ & $R_{\mathrm{D}}$ & $\mathrm{I}_{\mathrm{S}}$ \\
\hline$\alpha$ & 0.225 & & & & & \\
$\beta$ & 0.250 & -0.635 & & & & \\
$\gamma$ & -0.633 & 0.521 & $-0.879^{* *}$ & & & \\
$R_{\mathrm{D}}$ & $0.732^{*}$ & 0.192 & 0.228 & -0.488 & & \\
$\mathrm{I}_{\mathrm{S}}$ & 0.200 & 0.521 & $-0.841^{* *}$ & 0.504 & 0.196 & \\
$\mathrm{I}_{\mathrm{C}}$ & 0.676 & -0.059 & 0.382 & -0.615 & $0.968^{\text {****}}$ & 0.078 \\
\hline
\end{tabular}

temperature stress occurred, $\alpha$ decreased and $\mathrm{I}_{\mathrm{C}}$ increased for both varieties, with larger amplitude of variation in ROC22 than in GT02-467. The ability of sugarcane leaves using low light for photosynthesis decreased. High temperature had greater influences on photosynthesis at low light levels for ROC22 than for GT02-467. With higher

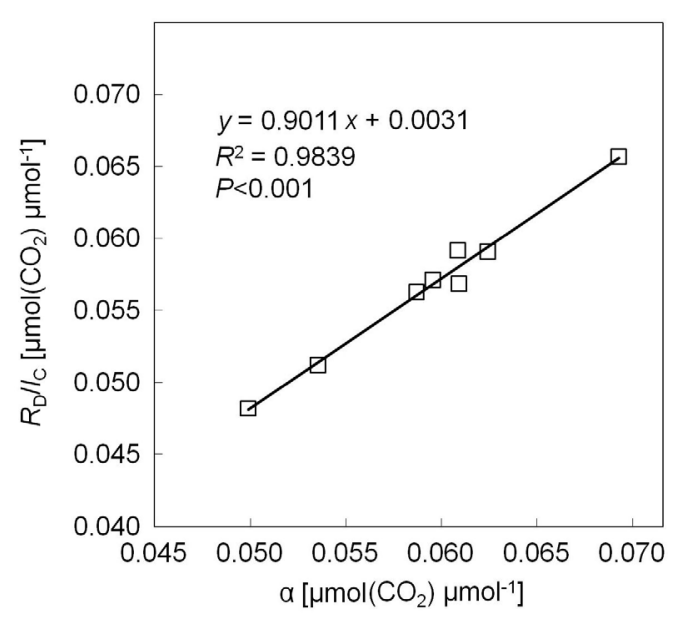

Fig. 2. Correlation between $R_{\mathrm{D}} / \mathrm{I}_{\mathrm{C}}$ and $\alpha$. All parameters were fitted by the Ye model. $\alpha$ - initial light-use efficiency; $R_{\mathrm{D}}-$ dark respiration rate; $\mathrm{I}_{\mathrm{C}}$ - light-compensation point. temperatures, both $\beta$ and $\gamma$ increased, and $\mathrm{I}_{\mathrm{S}}$ remained essentially unchanged for ROC22; but for GT02-467, both $\beta$ and $\gamma$ decreased and $I_{S}$ increased. Under high temperature stress, photosynthetic photoinhibition appeared in ROC22, not in GT02-467. $R_{\mathrm{D}}$ of ROC22 increased, but the $R_{\mathrm{D}}$ of GT02-467 basically remained unchanged (Table 3).

Comparison of photosynthetic light-response curves: Because of the almost nightly rainfall during the observation period, the average soil water content on photosynthesis measurement days was high in the $0-20-\mathrm{cm}$ layer (average value $0.34 \pm 0.06 \mathrm{~cm}^{3} \mathrm{~cm}^{-3}$ ). Relative humidity in the leaf chamber averaged $51 \%$. Nevertheless, under high temperatures $\left(34-39^{\circ} \mathrm{C}\right)$, photoinhibition of photosynthesis appeared in most sugarcane varieties, with only GT02-467 showing a decrease in photosynthetic rate instead of photoinhibition (Fig. 1).

The PLR parameters of different sugarcane varieties were compared using the Ye model (Table 1). The results showed that $P_{\text {gmax }}$ ranged from 21.1 to $33.0 \mu \operatorname{mol}\left(\mathrm{CO}_{2}\right)$ $\mathrm{m}^{-2} \mathrm{~s}^{-1}$. It was the greatest for YZ99-91 followed by YZ01-1413, and smallest for YZ03-194 and GT02-467. The $P_{\text {gmax }}$ of YZ99-91 and YZ01-1413 were obviously different from those of YZ03-194 and GT02-467 at 0.05 significance level. For $R_{\mathrm{D}}$ and $\mathrm{I}_{\mathrm{C}}, \mathrm{YZ01-1413}$ was the greatest, followed by YZ99-91, and both distinguished from other varieties at 0.05 significant level. $I_{S}$ was the largest for GT02-467 and smallest for YZ03-194, differed

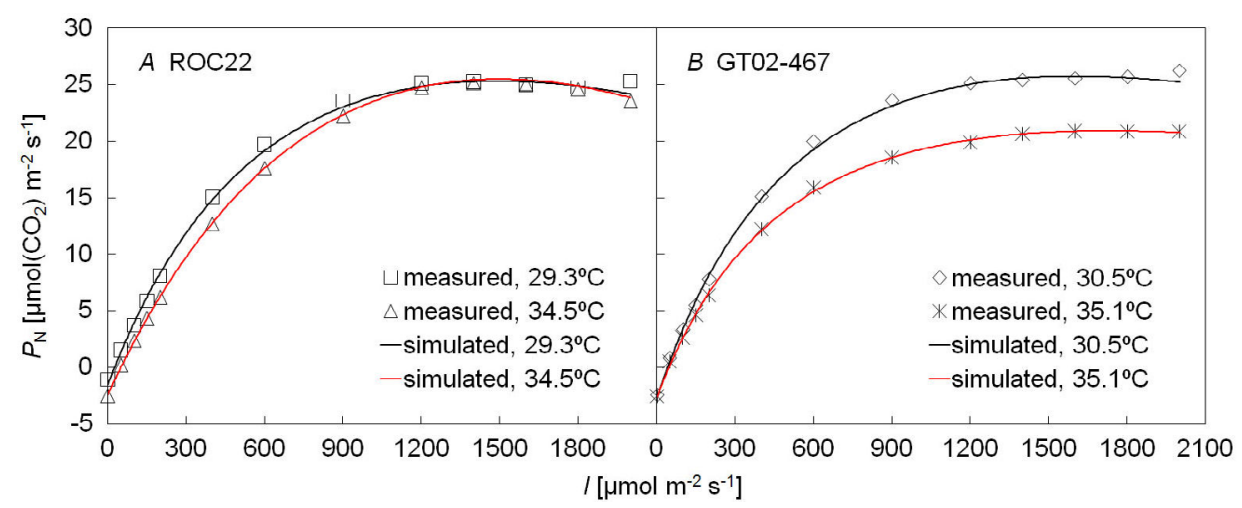

Fig. 3. Photosynthetic light-response curves for two sugarcane varieties under different temperatures. Data points were the average of three measurements, and the curves were fitted by the Ye model. $P_{\mathrm{N}}-$ net photosynthetic rate, $I-$ available photosynthetic photon flux density (PPFD). 
Table 3. Photosynthetic light-response parameters of two sugarcane varieties under different temperatures. The parameters were obtained by the Ye model. Each value was the average of three replications. The parameter abbreviations and symbols were defined in Table 1 , $T_{\mathrm{a}}$ - mean air temperature inside leaf chamber during observation period $\left[{ }^{\circ} \mathrm{C}\right]$.

\begin{tabular}{llllllllll}
\hline Variety & \multirow{2}{*}{$T_{\mathrm{a}}$} & \multicolumn{2}{c}{ Light-response parameters } & & & \multicolumn{2}{c}{$r^{2}$} \\
& & $P_{\operatorname{gmax}}$ & $\alpha$ & $\beta\left(\times 10^{-4}\right)$ & $\gamma\left(\times 10^{-4}\right)$ & $R_{\mathrm{D}}$ & $\mathrm{I}_{\mathrm{S}}$ & $\mathrm{I}_{\mathrm{C}}$ & \\
\hline GT02-467 & 35.1 & 20.90 & 0.061 & 1.3 & 4.5 & 2.61 & 1,723 & 46 & 1.000 \\
GT02-467 & 30.5 & 25.74 & 0.069 & 1.6 & 9.2 & 2.66 & 1,601 & 41 & 0.999 \\
ROC22 & 34.5 & 25.52 & 0.050 & 2.5 & 14.3 & 2.41 & 1,496 & 50 & 1.000 \\
ROC22 & 29.3 & 25.33 & 0.061 & 2.0 & 11.9 & 1.52 & 1,485 & 26 & 0.998 \\
\hline
\end{tabular}

with each other at 0.05 significance level. For GT02-467, the $\gamma$ value was the largest, while the $\beta$ value was the lowest among varieties. Both values of GT02-467 were discriminated from those of other varieties at 0.01 significance level. $\alpha$ was in the range of $0.051-0.062$, with maximum for YZ01-1413 and minimum for ROC22. However, there was no significant difference between varieties (Table 1).

\section{Discussion}

Comparison of photosynthetic light-response models: The results of this study showed that among the photosynthetic response parameters of sugarcane, $P_{\text {gmax }}$, $\mathrm{I}_{\mathrm{C}}$, and $R_{\mathrm{D}}$ were the best simulated by the Ye model, followed by the NRH model. $\alpha$ was best simulated by the NRH model, followed by the Ye model (Table 1). Wan et al. (2018) obtained similar results in a study of Epilobium angustifolium L. The RH model did not consider the degree of curvature of the PLR curve, so it was necessary to increase the initial slope in order to make the curve coincide with measured points (Johnson et al. 1989), which made the fitted $\alpha$ larger than the measured one. To solve the problem, Thornley et al. (1976) added a convexity term $(\theta)$ to the RH model and constructed the NRH model. The inflection point of the NRH model was more obvious than that of the RH model and the change was more gentle under high PPFD, leading to lower $P_{\text {gmax }}$ and $\alpha$ and photosynthetic rates closer to measured values (Koyama and Kikuzawa 2010, Calama et al. 2013). However, the PLR curves created by the RH and NRH models showed photosynthetic rate continuing to increase asymptotically with increasing PPFD. Because of this, the $\mathrm{I}_{\mathrm{S}}$ could not be determined, and $P_{\mathrm{gmax}}$ were overestimated (Chen et al. 2011, Yan et al. 2013). Neither the RH model nor the NRH model could adequately fit data points that were manifesting the effects of photoinhibition (Ye and Yu 2007). In order to solve these problems, Ye (2007) subtracted a factor from the RH model, and introduced the photoinhibition coefficient and the photosaturation coefficient and proposed the modified rectangular hyperbola model, later known as the Ye model (Lobo et al. 2013). IS and $P_{\text {gmax }}$ obtained by the Ye model were closer to the measured values (Wan et al. 2018). For sugarcanes, $R_{\mathrm{D}}$ was proportional to $P_{\mathrm{gmax}}$ and $\mathrm{I}_{\mathrm{C}}$ was proportional to $R_{\mathrm{D}}$ (Table 2), $P_{\text {gmax }}, \mathrm{I}_{\mathrm{C}}$, and $R_{\mathrm{D}}$ given by the Ye model were better than those by other models.
Correlations between photosynthetic light-response parameters: Among the PLR parameters, $P_{\text {gmax }}$ reflects the utilization capacity of high PPFD, $\alpha$ represents the utilization efficiency to low PPFD, and $\mathrm{I}_{\mathrm{C}}$ is the critical light intensity for plants to utilize low light levels. In this study, $P_{\text {gmax }}$ was positively correlated with $R_{\mathrm{D}}$ (Table 2 ). Sugarcane is a species with high light efficiency, therefore requiring more energy to maintain high photosynthetic rates, which in turn results in greater $R_{\mathrm{D}}$ (Kaipiainen 2009 ). We found that $\mathrm{I}_{\mathrm{C}}$ was positively correlated with $R_{\mathrm{D}}$ (Table 2). Greater dark respiration means higher PPFD was needed for photosynthesis to overcome the respiration under low light intensity. It was consistent with the findings of Gunasekera et al. (2013). IS is the light intensity when photosynthesis reaches the maximum value. The smaller the $\mathrm{I}_{\mathrm{S}}$ is, the easier to achieve $P_{\mathrm{gmax}}$, and the more likely that photoinhibition occurs. $\beta$ quantifies the degree of photoinhibition. When $\gamma$ is constant, the larger the $\beta$ is, the easier is to observe photoinhibition, and the smaller corresponding $\mathrm{I}_{\mathrm{S}}$ (Ye and Kang 2012). It is the reason why $\beta$ was negatively correlated with $\mathrm{I}_{\mathrm{S}}$ (Table 2). Ye et al. (2013) researched the light response of photosynthetic electron transport rate and point out that both $\beta$ and $\gamma$ were calculated by $g_{\mathrm{i}} / g_{\mathrm{k}}$. $\beta$ was negatively correlated with $g_{\mathrm{i}} / g_{\mathrm{k}}$ whereas $\gamma$ was positively correlated with $g_{\mathrm{i}} / g_{\mathrm{k}}\left(g_{\mathrm{i}}\right.$ and $g_{\mathrm{k}}$ was degeneration of energy level of photosynthetic pigment molecules in the ground state $i$ and the excited state $k$, respectively), leading to a negative correlation between $\beta$ and $\gamma$ (Table 2).

Effects of high temperature stress on photosynthetic light response: Photosynthesis is highly susceptible to temperature changes. For $\mathrm{C}_{4}$ species adapted to hot environments, such as millet and sugarcane, the optimum temperature of photosynthesis is around $30^{\circ} \mathrm{C}$ (Zhang et al. 1998, Al-Khatib and Paulsen 1999). In this study, net photosynthetic rate of sugarcane variety GT02-467 decreased after the temperature exceeded $30^{\circ} \mathrm{C}$, while variety ROC22 was not affected, but photoinhibition became more apparent at temperatures greater than $30^{\circ} \mathrm{C}$ (Fig. 3, Table 3). The former result was consistent with the studies on millet (Setaria italic L.), rice (Oryza sativa L.) (Al-Khatib and Paulsen 1999), and grapevines (Vitis vinifera L.) (Schultz 2003), while the latter result was similar to the report on Stylosanthes guianensias SW. (Mo et al. 2011). Under high temperatures, the decline in photosynthetic rate may attribute to stomata closure 
in leaves (Greer and Weedon 2012) and injury to the PSII of leaf chloroplasts (Al-Khatib and Paulsen 1999, Velikova et al. 2005, Bertamini et al. 2006). Differences in photosynthetic responses to high temperature stress are associated with light reactions, and extreme sensitivity of plant may be attributed to the damage in PSII (Al-Khatib and Paulsen 1999).

Our results showed that $\alpha$ decreased but $\mathrm{I}_{\mathrm{C}}$ increased for both sugarcane varieties GT02-467 and ROC22 when temperature exceeded $30^{\circ} \mathrm{C}$ (Table 3 ). The former was in agreement with the studies on potato (Solanum tuberosum L.) (Fleisher et al. 2006) and Dactylis glomerata L. (Peri et al. 2005), while the later was consistent with the research on white spruce (Picea glauca) (Man and Lieffers 1997), but at odds with the study on chestnut (Castanopsis tibetana) (Zhang and Luo 2016). Under high temperatures, some plants are more adaptable to low PPFD and others less adaptable to low PPFD, with differences possibly related to the different environmental conditions. In this research, $R_{\mathrm{D}}$ increased significantly for variety ROC22 but changed less for varieties GT02-467 when temperature was larger than $30^{\circ} \mathrm{C}$ (Table 3). Plant respiration is mainly controlled by temperature. The sensitivity of respiration to temperature was different between plant species. The optimum temperature range for respiration is wider than the optimum temperature range for photosynthesis, with respiration rate increasing exponentially with increasing temperature.

Photosynthetic characteristics: The Fifth Assessment Report (AR5) of the Intergovernmental Panel on Climate Change (IPCC 2013) indicated the global average temperature increased by $0.85^{\circ} \mathrm{C}$ from 1880 to 2012 , and predicted in its scenarios that global temperatures would rise about $0.3-4.8^{\circ} \mathrm{C}$ by the late $21^{\text {st }}$ century relative to 1986-2005. In the context of global climate change, China also experienced a warming trend (Weng and Zhou 2006). In the experimental area of this study, Yunnan, one of the main sugarcane producing areas in China, the summer temperature was predicted to increase by 1.7 and $2.75^{\circ} \mathrm{C}$ for 4.5 and 8.5 scenarios of RCPs in $2080 \mathrm{~s}$. In $2100 \mathrm{~s}$, the annual average temperature was predicted to increase by $4^{\circ} \mathrm{C}$ for the 8.5 scenarios (Liu et al. 2017). Therefore, in the future, maximum air temperatures will frequently be higher than the optimal temperature for sugarcane photosynthesis, threatening sugarcane production.

Guangxi and Fujian (south-central and southeast China, respectively) have abundant precipitation and frequent cloudy, low radiation conditions. Sugarcane varieties GT02-467 from Guangxi and MT69-421 from Fujian have low utilization capacity for high PPFD conditions, but high utilization efficiency to low PPFD conditions (Table 3). These varieties are, therefore, suitable for planting under such climatic conditions as found at Guangxi and Fujian and at high planting density in future climate scenarios. Among the six sugarcane varieties, YZ99-91 and YZ01-1413 from Yunnan have the highest utilization efficiency to both high and low PPFD, but the $R_{\mathrm{D}}$ and the critical light intensity for utilizing low PPFD were also the highest (Table 3), thereby making utilization of low PPFD particularly difficult. Generally speaking, YZ99-91 and YZ01-1413 are suitable for planting on the Yunnan Plateau where high PPFD conditions are found and the planting density can be higher in future climate scenarios. Although YZ03-194 is also from Yunnan, it has lower utilization efficiency of both high and low PPFD, and frequently encounters conditions that promote photoinhibition. It is, therefore, a variety that is not suitable for planting on the Yunnan Plateau in future climate scenarios because of the high radiation conditions found there. It may also not be suitable for low radiation environments and should not be managed under high planting density.

Variety ROC22, introduced from Taiwan, is characterized by high bud germination, fast growth, high plant height, abundant and homogeneous millable stalks, lodging resistance, and drought resistance (Zhao et al. 2016). It is the most widely grown sugarcane variety in China with the largest planted area. However, ROC22 has no advantage in photosynthesis compared to other varieties in this study, and the light-utilization capacity at high PPFD was lowered. Its critical light intensity for utilizing low PPFD and the utilization efficiency to low radiation were the lowest of the six varieties tested in this experiment. In terms of photosynthetic characteristics, ROC22 is not suitable for planting in such climate conditions as found at Guangxi in future climate scenarios, and should not be planted too densely.

Conclusions: Even in the moist conditions, photoinhibition of photosynthesis appeared under high temperature stress for most sugarcane varieties except for GT02-467, which showed a decrease in photosynthetic rate instead of photoinhibition. When temperature increased from about $30^{\circ} \mathrm{C}$ to about $35^{\circ} \mathrm{C}$, maximum gross photosynthetic rate reduced obviously for GT02-467 but kept unchanged for ROC22, whereas dark respiration rate enlarged significantly for ROC22 but remained constant for GT02-467. For both varieties, initial light-use efficiency declined and light-compensation point enhanced, with amplitudes of variations greater for ROC22 than GT02-467.

The photosynthetic light-response curves simulated by the Ye model coincided well with the measured values under all tested situations, and the model was especially good at simulating photoinhibition. Both the nonrectangular hyperbola model and the Ye model provided good simulation results when there was no photoinhibition. Among the fitting parameters for the photosynthetic lightresponse curves, maximum net photosynthetic capacity, light-compensation point, and dark respiration rate were all simulated best by the Ye model, while initial lightuse efficiency was simulated best by the nonrectangular hyperbola model. Of the three models tested in this study, the rectangular hyperbola model was the least accurate in simulating the photosynthetic light-response curves.

The variety with high light efficiency required more energy to maintain high photosynthetic rates, resulting in greater dark respiration rate, which means higher PPFD is needed for photosynthesis to overcome the respiration under low light intensity. The smaller the light-saturation point is, the easier to achieve maximum photosynthetic 
rate, and the more likely that photoinhibition occurs, leading to a large photoinhibition coefficient. The ratio of the ground state to the excited state for the energy level degeneration of photosynthetic pigment molecules was negatively correlated with photoinhibition coefficient but positively correlated with photosaturation coefficient, leading to a negative correlation between photoinhibition coefficient and photosaturation coefficient.

Considering the use of the six sugarcane varieties under future climate scenarios, precocious variety YZ99-91 and medium-ripe/high-yield variety YZ01-1413 had the highest maximum photosynthetic capacity, dark respiration rate, initial light-use efficiency, and lightcompensation point, suggesting that planting density could be higher. Precocious/high-yield variety GT02-467 and medium-ripe variety MT69-421 had lower maximum photosynthetic capacity but higher initial light-use efficiency, and are suitable for planting in lower radiation areas. Medium precocious/high-yield variety YZ03-194 and medium-ripe/high-yield variety ROC22 had lower maximum photosynthetic capacity and initial light-use efficiency, suggesting that they are not suitable for high density planting.

\section{References}

Al-Khatib K., Paulsen G.M.: High-temperature effects on photosynthetic processes in temperate and tropical cereals. Crop Sci. 39: 119-125, 1999.

Baly E.C.C.: Kinetics of photosynthesis. - P. Roy. Soc. Lond. B Bio. 117: 218-239, 1935.

Bassman J.H., Zwier J.C.: Gas exchange characteristics of Populus trichocarpa, Populus deltoides and Populus trichocarpa $\times$ P. deltoides clones. - Tree Physiol. 8: 145-159, 1991.

Berry J., Björkman O.: Photosynthetic response and adaptation to temperature in higher plants. - Ann. Rev. Plant Physio. 31: 491-543, 1980.

Bertamini M., Muthuchelian K., Rubinigg M. et al.: Low-night temperature increased the photoinhibition of photosynthesis in grapevine (Vitis vinifera L. cv. Riesling) leaves. - Environ. Exp. Bot. 57: 25-31, 2006.

Bruzzese B.M., Bowler R., Massicotte H.B., Fredeen A.L.: Photosynthetic light response in three carnivorous plant species: Drosera rotundifolia, D. capensis and Sarracenia leucophylla. - Photosynthetica 48: 103-109, 2010.

Calama R., Puértolas J., Madrigal G., Pardos M.: Modeling the environmental response of leaf net photosynthesis in Pinus pinea L. natural regeneration. - Ecol. Model. 251: 9-21, 2013.

Chen Z.Y., Peng Z.S., Yang J. et al.: A mathematical model for describing light-response curves in Nicotiana tabacum L. Photosynthetica 49: 467-471, 2011.

Crafts-Brandner S.J., Salvucci M.E.: Sensitivity of photosynthesis in $\mathrm{C}_{4}$ plant, maize, to heat stress. - Plant Physiol. 129: 17731780, 2002.

Dwyer P.J., Bannister P., Jameson P.E.: Effects of three plant growth regulators on growth, morphology, water relations, and frost resistance in lemonwood (Pittosporum eugenioides A. Cunn). - New Zeal. J. Bot. 33: 415-424, 1995.

Fleisher D.H., Timlin D.J., Reddy V.R.: Temperature influence on potato leaf and branch distribution and on canopy photosynthetic rate. - Agron. J. 98: 1442-1452, 2006.

Greer D.H., Weedon M.M.: Modelling photosynthetic responses to temperature of grapevine (Vitis vinifera cv. Semillon) leaves on vines grown in a hot climate. - Plant Cell Environ. 35: 1050-1064, 2012.

Gunasekera H.K.L.K., De Costa W.A.J.M., Nugawela A.: Canopy photosynthetic capacity and light response parameters of rubber Hevea brasiliensis with reference to exploitation. Curr. Agr. Res. J. 1: 1-12, 2013.

Hirose T., Werger M.J.A.: Nitrogen use efficiency in instantaneous and daily photosynthesis of leaves in the canopy of a Solidago altissima stand. - Physiol. Plantarum. 70: 215-222, 1987.

Inman-Bamber N.G., Thompson G.D.: Models of dry matter accumulation by sugarcane. - In: Proceedings of the Annual Congress - South African Sugar Technologists' Association. Pp. 212-216. SASTA, 1989.

IPCC: Climate Change 2013: The Physical Science Basis. Contribution of Working Group I to the Fifth Assessment Report of the Intergovernmental Panel on Climate Change. Pp. 222. Cambridge University Press, Cambridge-New York 2013.

Johnson I.R., Parsons A.J., Ludlow M.M.: Modelling photosynthesis in monocultures and mixtures. - Aust. J. Plant Physiol. 16: 501-516, 1989.

Kaipiainen E.L.: Parameters of photosynthesis light curve in Salix dasyclados and their changes during the growth season. - Russ. J. Plant Physl+ 56: 445-453, 2009.

Koyama K., Kikuzawa K: Geometrical similarity analysis of photosynthetic light response curves, light saturation and light use efficiency. - Oecologia 164: 53-63, 2010.

Kyei-Boahen S., Lada R., Astatkie T. et al.: Photosynthetic response of carrots to varying irradiances. - Photosynthetica 41: 301-305, 2003.

Lang Y., Wang M., Zhang G.C., Zhao K.Q.: Experimental and simulated light responses of photosynthesis in leaves of three tree species under different soil water conditions. Photosynthetica 51: 370-378, 2013.

Leakey A.D.B., Uribelarrea M., Ainsworth E.A. et al.: Photosynthesis, productivity, and yield of maize are not affected by open-air elevation of $\mathrm{CO}_{2}$ concentration in the absence of drought. - Plant Physiol. 140: 779-790, 2006.

Leverenz J.W., Jarvis P.G.: Photosynthesis in Sitka spruce. VIII. The effects of light flux density and direction on the rate of net photosynthesis and the stomatal conductance of needles. J. Appl. Ecol. 16: 919-932, 1979.

Liu J.X., Chen S.J., Li L.J., Li J.Y.: Statistical downscaling and projection of future air temperature changes in Yunnan Province, China. - Adv. Meteorol. 2017: 11, 2017.

Lobo F.D.A., Barros M.P.D., Dalmagro H.J. et al.: Fitting net photosynthetic light-response curves with Microsoft Excel a critical look at the models. - Photosynthetica 51: 445-456, 2013.

Man R., Lieffers V.J.: Seasonal photosynthetic responses to light and temperature in white spruce (Picea glauca) seedlings planted under an aspen (Populus tremuloides) canopy and in the open. - Tree Physiol. 17: 437-444, 1997.

Mo Y.W., Guo Z.F., Xie J.H.: [Effects of temperature stress on chlorophyll fluorescence parameters and photosynthetic rates of Stylosanthes guianensis.] - Acta Pratacult. Sin. 20: 96-101, 2011. [In Chinese with English abstract]

Moore P.H., Botha F.C.: Photosynthesis in sugarcane. - In: Moore P.H., Botha F.C. (ed.): Sugarcane Physiology, Biochemistry and Functional Biology. Pp. 121-149. Blackwell, New Jersey 2014.

Nepstad D.C., Moutinho P., Dias-Filho M.B. et al.: The effects of partial throughfall exclusion on canopy processes, aboveground production, and biogeochemistry of an Amazon forest. - J. Geophys. Res. 107: LBA 53-1-LBA 53-18, 2002. 
Ogren E: Convexity of the photosynthetic light-response curve in relation to intensity and direction of light during growth. Plant Physiol. 101: 1013-1019, 1993.

Peri P.L., Moot D.J., McNeil D.L. et al.: Modelling photosynthetic efficiency $(\alpha)$ for the light-response curve of cocksfoot leaves grown under temperate field conditions. - Eur. J. Agron. 22: 277-292, 2005.

Prado C.H.B.A., De Moraes J.A.P.V.: Photosynthetic capacity and specific leaf mass in twenty woody species of Cerrado vegetation under field conditions. - Photosynthetica 33: 103$112,1997$.

Rascher U., Liebig M., Lüttge U.: Evaluation of instant lightresponse curves of chlorophyll fluorescence parameters obtained with a portable chlorophyll fluorometer on site in the field. - Plant Cell Environ. 23: 1397-1405, 2000.

Read J., Hill R.S.: Dynamics of Nothofagus-dominated rainforest on mainland Australia and lowland Tasmania. - Vegetatio 63: 67-78, 1985.

Salvucci M.E., Crafts-Brandner S.J.: Relationship between the heat tolerance of photosynthesis and the thermal stability of Rubisco activase in plants from contrasting thermal environments. - Plant Physiol. 134: 1460-1470, 2004.

Schultz H.R.: Extension of a Farquhar model for limitations of leaf photosynthesis induced by light environment, phenology and leaf age in grapevines (Vitis vinifera L. cvv. White Riesling and Zinfandel). - Funct. Plant Biol. 30: 673-687, 2003.

Sun O.J., Sweet G.B.: Genotypic variation in light and temperature response of photosynthesis in Nothofagus solandri var. cliffortioides and $N$. menziesii. - Funct. Plant Biol. 23: 421-428, 1996.

Thornley J.H.M.: Mathematical Models in Plant Physiology. Pp. 318. Academic Press, London 1976.

Thornley J.H.M.: Dynamic model of leaf photosynthesis with acclimation to light and nitrogen. - Ann. Bot.-London 81: 421-430, 1998.

Velikova V., Pinelli P., Loreto F.: Consequences of inhibition of isoprene synthesis in Phragmites australis leaves exposed to elevated temperatures. - Agr. Ecosyst. Environ. 106: 209-217, 2005.

Wan L.S., Xing Z., Chang X.Y. et al.: Research on light response curve fitting model of four Chamaenerion plants on the Serzilla Mountains. - Am. J. Plant Sci. 9: 1630-1645, 2018.

Weng E.S., Zhou G.S.: Modeling distribution changes of vegetation in China under future climate change. - Environ. Model. Assess. 11: 45-58, 2006.

Yan X.H., Yin J.H., Duan S.H. et al.: [Photosynthesis light response curves of four rice varieties and model fitting.] Chin. J. Ecol. 32: 604-610, 2013. [In Chinese with English abstract]

Ye Z.P., Hu W.H., Xiao Y.A. et al.: [A mechanistic model of lightresponse of photosynthetic electron flow and its application.] Chin. J. Plant Ecol. 38: 1241-1249, 2014. [In Chinese with English abstract]

Ye Z.P.: A new model for relationship between irradiance and the rate of photosynthesis in Oryza sativa. - Photosynthetica 45: 637-640, 2007.

Ye Z.P., Kang H.J.: [Study on biological significance of coefficients in modified model of photosynthesis-irradiance.] J. Yangzhou Univ. 33: 51-57, 2012. [In Chinese with English abstract]

Ye Z.P., Yu Q.: [Comparison of a new model of light response of photosynthesis with traditional models.] - J. Shenyang Agr. Univ. 38: 771-775, 2007. [In Chinese with English abstract]

Zhang B., Luo X.L.: [Effect of temperature on light response curve fitting of Castanopsis tibetana.] - J. Centr. South Univ. Forest Technol. 36: 55-60, 2016. [In Chinese with English abstract]

Zhang M.Q., Lv J.L., Chen R.K.: [Diurnal variation of photosynthetic rate in sugarcane and its responses to light and temperature.] - J. Fujian Agr. Univ. 27: 397-401, 1998. [In Chinese with English abstract]

Zhao P.F., Xia H.M., Yang K. et al.: Sugarcane yield components and sugar content in ROC22 progeny populations. - Int. Sugar J. 118: 26-33, 2016.

(C) The authors. This is an open access article distributed under the terms of the Creative Commons BY-NC-ND Licence. 